\title{
Fourth molar: A retrospective study and literature review of a rare clinical entity
}

\author{
Babatunde O. Bamgbose $\mathbb{D}^{1,2, *}$, Shunsuke Okada $\mathbb{D}^{3}$, Miki Hisatomi $\mathbb{D}^{3}$, Yoshinobu Yanagi $\mathbb{D}^{4,5}$,

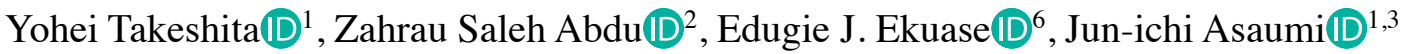 \\ ${ }^{1}$ Department of Oral and Maxillofacial Radiology, Okayama University Graduate School of Medicine, Dentistry and Pharmaceutical \\ Sciences, Okayama, Japan \\ ${ }^{2}$ Department of Oral Diagnostic Sciences, Faculty of Dentistry, Bayero University Kano, Kano, Nigeria \\ ${ }^{3}$ Department of Oral Diagnosis and Dentomaxillofacial Radiology, Okayama University Hospital, Okayama, Japan \\ ${ }^{4}$ Department of Dental Informatics, Okayama University Graduate School of Medicine, Dentistry and Pharmaceutical Sciences, \\ Okayama, Japan \\ ${ }^{5}$ Oral Inspection and Diagnostic Center, Okayama University Hospital, Okayama, Japan \\ ${ }^{6}$ Department of Chemistry and Forensic Sciences, Savannah State University, Georgia, USA
}

\section{ABSTRACT}

Purpose: The prevalence of supernumerary teeth has been reported to be between $0.1 \%$ and $3.8 \%$. The aim of this study was to determine the prevalence, clinical significance, and associated pathologies of fourth molars based on a retrospective study and a literature review.

Materials and Methods: A 5-year retrospective prevalence study was conducted at the Department of Oral Diagnosis and Dentomaxillofacial Radiology of Okayama University Hospital, Okayama, Japan. The study involved extracting data from the digital records of patients from January 1, 2013 through December 31, 2017. The sampling frame included all patients who had panoramic radiographs, cone-beam computed tomography (CT), and multislice CT images during the period under review.

Results: A total of 26,721 cases were reviewed and 87 fourth molars were identified. The prevalence of fourth molars in the 5-year study at Okayama was calculated as $0.32 \%$. The mean age of patients with a fourth molar was 30.43 years, and the male-to-female ratio was 1:0.98. The vast majority of cases were in the maxilla (92\%) and had normal shapes (89.7\%); furthermore, $82.8 \%$ of cases were unerupted.

Conclusion: The prevalence of fourth molars in the study population was found to be $0.32 \%$, and fourth molars occurred with approximately equal frequency in males and females. Fourth molars were more common in the maxilla and were predominantly unerupted and small.(Imaging Sci Dent 2019; 49: 27-34)

KEY WORDS: Tooth, Supernumerary; Odontoma; Odontogenic Cyst

\section{Introduction}

Supernumerary teeth are extra teeth occurring in addition to the physiologic number of teeth, and they can be observed in both primary and permanent dentitions. ${ }^{1}$ Supernumerary teeth can be classified according to their location,

*This study was approved by the Institutional Review Board (Ethics Committee) of Okayama University, Okayama with the approval number 1804-018.

Received October 8, 2018; Revised November 28, 2018; Accepted December 15, 2018 *Correspondence to : Dr. Babatunde O. Bamgbose

Department of Oral and Maxillofacial Radiology, Okayama University Graduate School of Medicine, Dentistry and Pharmaceutical Sciences, 5-1, Shikata-Cho, 2-Chome, Kita-Ku, Okayama, Japan 700-8558

Tel) 81-86-235-6705, E-mail) drtundebamgbose@yahoo.com and those that erupt distal to the third molar are referred to as distomolars or fourth molars. ${ }^{2}$

Supernumerary teeth can be single or multiple and can occur in association with certain head and neck syndromes, including cleidocranial dysostosis, Gardner syndrome, Ehlers-Danlos syndrome, Fabry-Anderson syndrome, and cleft palate. ${ }^{3,4}$ They are morphologically classified as supplemental, conoid, tuberculate, infundibuliform or invaginated, and odontoma-like. Supernumerary teeth and odontomas may be the expression of the same pathologic process. $^{1}$

The prevalence of supernumerary teeth has been re-

Copyright (c) 2019 by Korean Academy of Oral and Maxillofacial Radiology

This is an Open Access article distributed under the terms of the Creative Commons Attribution Non-Commercial License (http://creativecommons.org/licenses/by-nc/3.0) which permits unrestricted non-commercial use, distribution, and reproduction in any medium, provided the original work is properly cited. Imaging Science in Dentistry · pISSN 2233-7822 eISSN 2233-7830 
ported to be between $0.1 \%$ and $3.8 \% .^{5-7}$ The diagnosis of fourth molars relies on imaging findings on periapical radiographs, panoramic radiographs, and computed tomography (CT). In addition, the availability of cone-beam CT (CBCT) has given oral and maxillofacial radiologists the option of using a smaller and less expensive machine for the 3-dimensional representation of the maxillofacial region at a lower level of radiation than occurs with multislice CT (MSCT) ${ }^{8}$ The clinical significance of a supernumerary tooth depends on its position and the likelihood of eruption into the dental arch. ${ }^{5}$ Extraction of a fourth molar can be complicated by displacement into the infratemporal fossa or the maxillary sinus, especially if the bone distal to the fourth molar is thin. ${ }^{9}$ It has further been suggested that prolonged retention of a fourth molar is a possible etiologic factor in the development of odontogenic inflammation, odontogenic cysts, periodontal disease, and neuralgic pain. ${ }^{10}$ Therefore, it may be necessary to study the kinetic behavior of fourth molars.

The aim of this study was to determine the prevalence, clinical significance, and associated pathologies of fourth molars through a retrospective analysis and a literature review.

\section{Materials and Methods}

A 5-year retrospective prevalence study was conducted at the Department of Oral Diagnosis and Dentomaxillofacial Radiology of Okayama University Hospital, Okayama, Japan. The study involved extracting data from the digital records of research subjects from January 1, 2013 through December 31, 2017. This study was approved by the Institutional Review Board (Ethics Committee) of Okayama University, Okayama with the approval number 1804-018.

All research subjects who had panoramic radiographs, and possibly either CBCT or multislice computed tomography (MSCT) images, during the period under review were recruited for the study. The picture archiving and communications system filter was set to include all panoramic radiographs obtained within the study period. Panoramic radiographs were the first images reviewed and, where available, advanced images-CBCT and MSCT - were subsequently reviewed to further define the characteristics of fourth molars, if present. Potential images were viewed with a digital magnifying glass under suitable viewing conditions to properly ascertain the possibility of a fourth molar in the region of the third molars.

If it was difficult to determine whether the tooth was a third or a fourth molar, all the authors, including 2 special- ists of the Japanese Society of Oral and Maxillofacial Radiology, were invited to review the images independently. Where no consensus could be reached, the case was classified as "cannot be decided" and excluded from the total number of fourth molars in the study.

A literature search for relevant studies was carried out using PubMed, Scopus and Google Scholar. The Boolean operator "AND" was used for the following key words: tooth, supernumerary, odontoma, and odontogenic cyst. Relevant references in the cited studies were also included in the review process.

\section{Inclusion criteria}

Research subjects were required to be at least 18 years of age. Only research subjects with panoramic radiographs were recruited for the study. The first panoramic radiograph must have been obtained within the period of the study. To avoid duplicates, in cases where a research subject had multiple images, the oldest images within the study period were selected. Only images taken at the Department of Oral Diagnosis and Dentomaxillofacial Radiology of Okayama University Hospital were included in the study. In cases with multiple fourth molars, each tooth was counted to determine the total number of fourth molars. Each subject was recorded as a case for the purposes of determining the sex predilection.

\section{Exclusion criteria}

Research subjects for whom the first panoramic radiograph was obtained outside the study period were excluded from the study. The records and images of research subjects with no entries in the age field were excluded from the study. External images imported into the imaging system were disregarded, and poor-quality images were also excluded from the study.

The selected cases were evaluated, and information was extracted on age, sex, and the date of the images. Notes were made regarding the type of images, the location and type of eruption, and the shape of fourth molars. The morphology of fourth molars was classified as normal or abnormal.

\section{Clinical significance and associated pathologies}

An investigation was also conducted to determine whether any cases were associated with lesions or systemic diseases or syndromes. These parameters were evaluated by a review of patients' medical records and images. When present, the location of any associated lesions or pathologies around the crown or roots of the fourth molar was noted. Cases with 

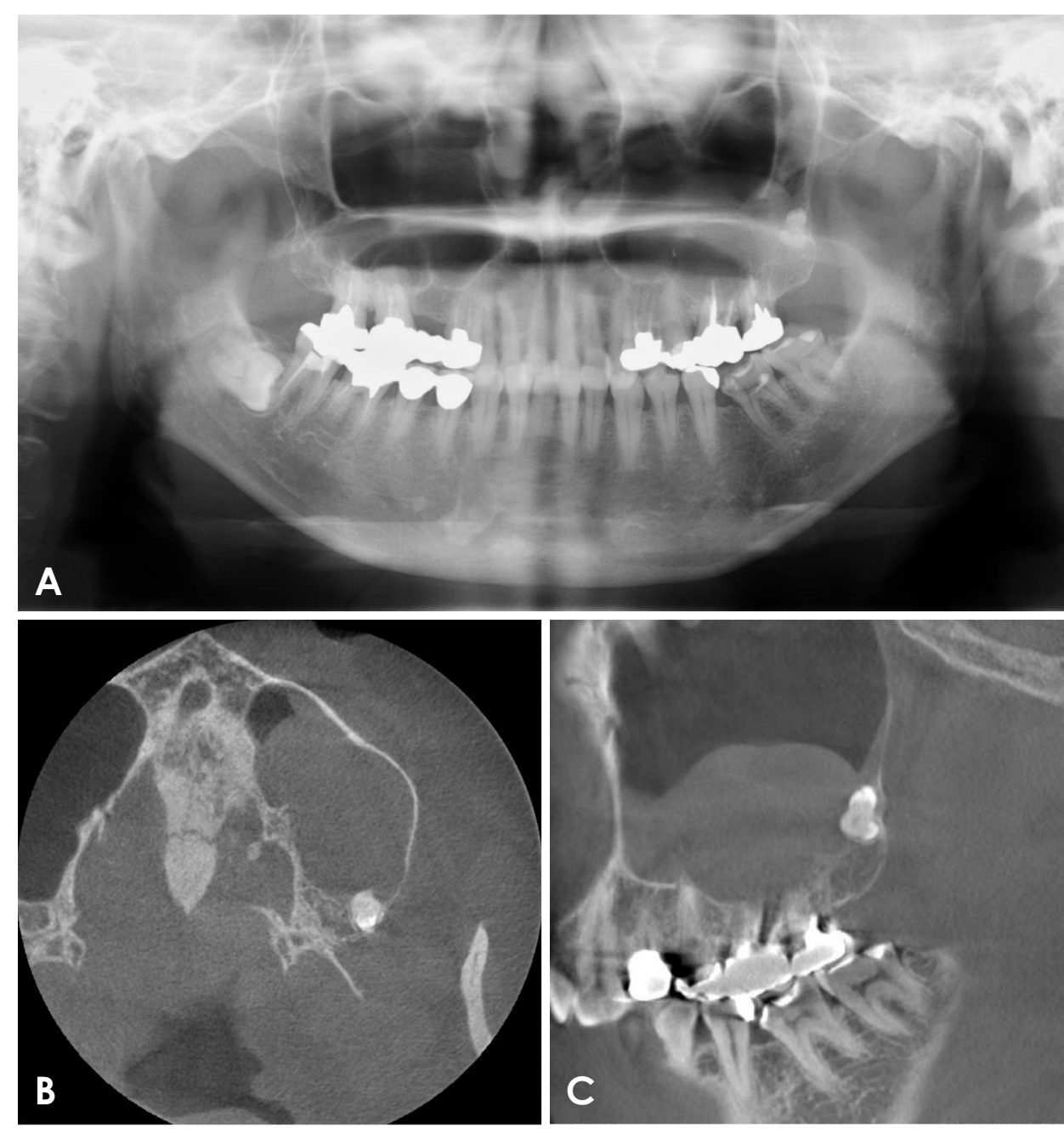

Fig. 1. A. Panoramic radiograph shows a borderline case classified as "cannot decide," portraying a toothlike radiopacity in posterior maxillary left region that cannot be classified as a third or fourth molar because of the absence of both maxillary third molars. B and C. Conebeam computed tomographic images demonstrate an abnormally shaped tooth-like entity with 2 distinct crowns and fused roots with an associated mucus retention cyst in the posterior wall of the maxillary sinus. clinical significance were defined as those that were symptomatic and needed treatment. Such cases were identified from patients' records and the nature of the recorded treatment. Patients' images and medical records were reviewed to determine the presence of any associated syndromes.

\section{Data management}

A descriptive statistical analysis was performed, and data were analyzed using SPSS (IBM Corp., Armonk, NY, USA). A simple descriptive analysis of central tendencies of patient demographics was conducted using means and modes. The prevalence of fourth molars was calculated by dividing the number of fourth molars by the total number of cases reviewed. Associations between morphology and position were analyzed using the Pearson chi-square test, the Friedman test, and the Mann-Whitney U test. $P$ values $<0.05$ were considered to indicate statistical significance. The Shapiro-Wilk test was used to determine the normality of data distribution.

\section{Results}

A total of 26,721 cases were reviewed, and 87 fourth molars were identified. The prevalence of fourth molars in this 5 -year study at Okayama University Hospital was calculated as $0.32 \%$.

The authors could not arrive at a consensus regarding the classification of 15 cases as either third or fourth molars. Such cases were classified as "cannot be decided" and were not included in the total number of fourth molars in the study. A typical borderline case is presented in Figure 1 , showing a missing maxillary left third molar and 2 fused toothlike structures with apparent crown morphologies, but indistinct root structures in the postero-inferior walls of the maxillary sinus. The appearance is suggestive of 2 teeth, but a determination could not be made whether they were third and fourth molars.

The patients with fourth molars consisted of 44 men and 43 women, ranging in age from 18 to 68 years, with a 

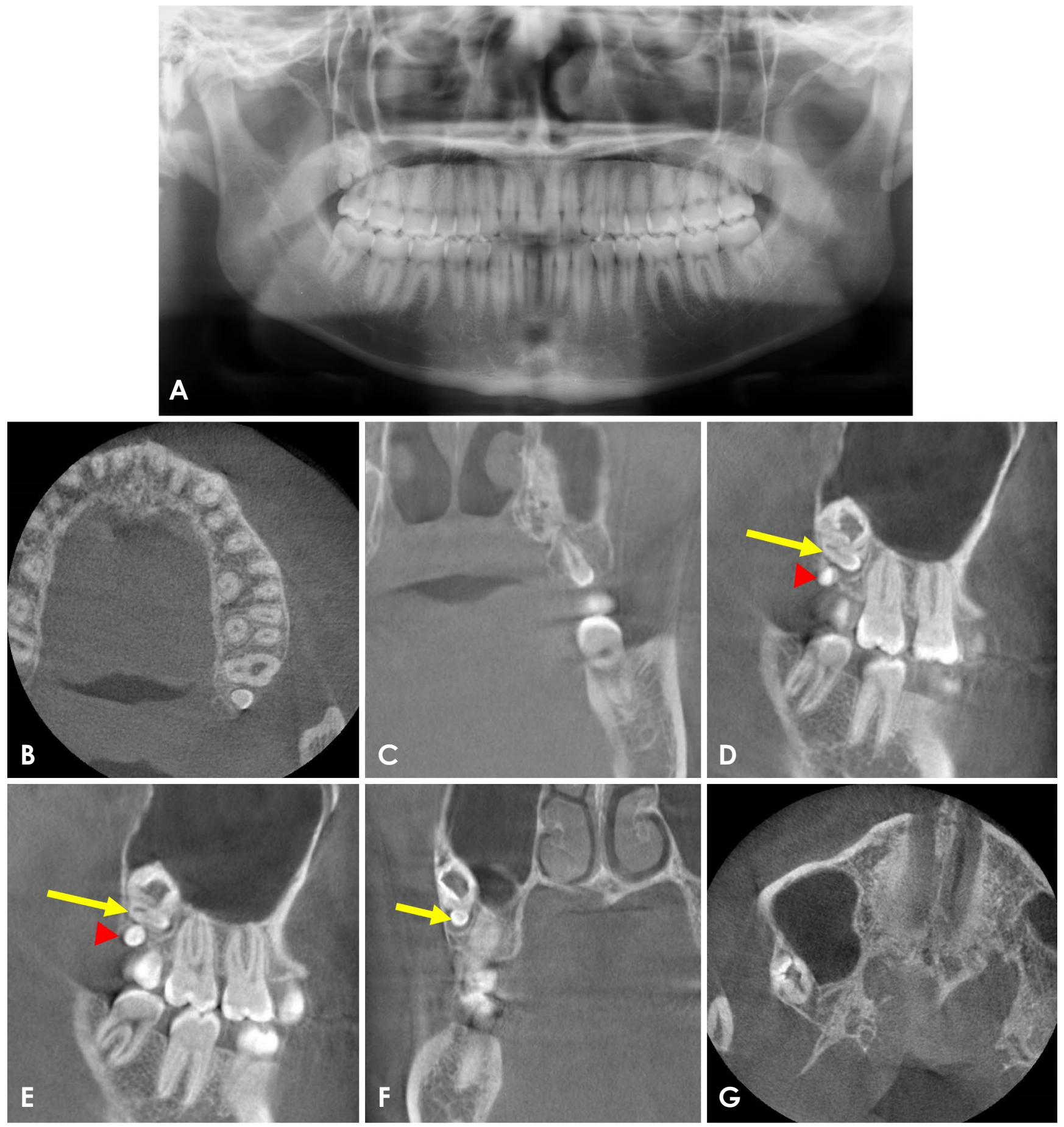

Fig. 2. A. Panoramic radiograph shows a fourth molar distal to the maxillary left third molar. There is also a fourth molar associated with a suspected odontoma in the region of the maxillary right third molar. Both fourth molars are in the maxillary tuberosity. B and C. Conebeam computed tomographic (CBCT) images demonstrate the maxillary left fourth molar as a normal-shaped microdont. D and E. Sagittal CBCT images show a complex odontoma superior to the maxillary right fourth molar (arrow head). D-G. The complex odontoma consists of a horizontally impacted microdont at its inferior segment (arrow), and the upper segment consists of various component tissues of the teeth.

mean age of 30.43 years. Eighty of the fourth molars were located in the maxilla, and 7 were located in the mandible. Seventy-eight of the fourth molars were normally shaped, and 9 were abnormally shaped. The vast majority of the cases were in the maxilla (92.0\%) and had normal morphology $(89.7 \%)$. Table 1 portrays a summary of the results 
of this study, including the location and shape of the fourth molars. Table 2 displays the detailed radiologic characteristics of the abnormally shaped fourth molars. A case of an unerupted normal-shaped microdont, representing a fourth molar with associated complex odontoma, is presented in Figure 2. Fusion was another associated pathology reported in 3 cases in the study (Fig. 3).

Seventy-two cases $(82.8 \%)$ were unerupted, 5 cases (5.7\%) were partially erupted, and 10 cases (11.5\%) were fully erupted. The Friedman test indicated a statistically significant difference in the pattern of eruption and anatomic location of the fourth molars. The Pearson chi-square test indicated a correlation between maxillary location of a fourth molar and an abnormal shape (2-sided asymptotic significance of 0.003$)$. The Mann-Whitney $U$ test value of $0.276(P>0.05)$ indicated no significant difference between locations. The Shapiro-Wilk test of significance was $<0.05$.
No cases presented with enlargement of an dental follicle, which may have suggested a dentigerous cyst. A fourth molar was associated with a relevant syndrome in 1 of the 87 cases in our study. Figure 4 presents a fourth molar in a patient with cleidocranial dysostosis. Mucous retention cyst, which was observed in 2 cases, was another pathology associated with fourth molars in our study.

Table 1. Summary of the location and shape of fourth molars

\begin{tabular}{lrcc}
\hline \multicolumn{1}{c}{ Location } & \multirow{2}{*}{ Number } & \multicolumn{2}{c}{ Shape } \\
& & Normal & Abnormal \\
\hline Maxillary right quadrant & 32 & 30 & 2 \\
Maxillary left quadrant & 48 & 44 & 4 \\
Mandibular left quadrant & 5 & 3 & 2 \\
Mandibular right quadrant & 2 & 1 & 1 \\
\hline \multicolumn{1}{c}{ Total } & 87 & 78 & 9 \\
\hline
\end{tabular}

Table 2. Summary of abnormally shaped fourth molars

\begin{tabular}{|c|c|c|c|c|c|}
\hline Age/Sex & $\begin{array}{l}\text { Imaging } \\
\text { modalities }\end{array}$ & Location & Shape & $\begin{array}{l}\text { Type of } \\
\text { eruption }\end{array}$ & Radiologic features \\
\hline $20 / \mathrm{F}$ & $\begin{array}{l}\text { Pano }+ \\
\text { CBCT }\end{array}$ & $\begin{array}{l}\text { Maxillary left } \\
\text { quadrant }\end{array}$ & $\begin{array}{l}\text { Abnormal crown } \\
\text { morphology }\end{array}$ & Unerupted & $\begin{array}{l}\text { A large tooth, representing the fourth molar, and } 3 \\
\text { denticles located in the maxillary tuberosity in the } \\
\text { proximity of the floor of the maxillary sinus. }\end{array}$ \\
\hline $32 / \mathrm{M}$ & Pano & $\begin{array}{l}\text { Mandibular right } \\
\text { quadrant }\end{array}$ & $\begin{array}{l}\text { Abnormal crown } \\
\text { morphology }\end{array}$ & Unerupted & $\begin{array}{l}\text { Abnormal crown morphology. Roots not portrayed on } \\
\text { the image. Impacted and distal to the adjacent third } \\
\text { molar. }\end{array}$ \\
\hline $56 / \mathrm{M}$ & Pano $+\mathrm{CT}$ & $\begin{array}{l}\text { Maxillary left } \\
\text { quadrant }\end{array}$ & Toothlike structure & Unerupted & $\begin{array}{l}\text { Distinct abnormal crown morphology, but the outline } \\
\text { of roots was not distinct. Located in the maxillary } \\
\text { tuberosity. Horizontally impacted against the root of the } \\
\text { associated third molar, facing distally. }\end{array}$ \\
\hline $51 / \mathrm{M}$ & Pano $+\mathrm{CT}$ & $\begin{array}{l}\text { Maxillary right } \\
\text { quadrant }\end{array}$ & Toothlike structure & Unerupted & $\begin{array}{l}\text { Located palatally in the maxillary tuberosity distal to the } \\
\text { associated third molar. }\end{array}$ \\
\hline $66 / F$ & $\begin{array}{l}\text { Pano }+ \\
\text { CBCT }\end{array}$ & $\begin{array}{l}\text { Mandibular left } \\
\text { quadrant }\end{array}$ & Toothlike structure & Unerupted & $\begin{array}{l}\text { Impacted third molar with associated unerupted, poorly } \\
\text { formed fourth molar. The fourth molar was located distal } \\
\text { and buccal to the impacted third molar. Root morphology } \\
\text { not distinct. }\end{array}$ \\
\hline $46 / \mathrm{M}$ & Pano & $\begin{array}{l}\text { Maxillary left } \\
\text { quadrant }\end{array}$ & Toothlike structure & Unerupted & $\begin{array}{l}\text { Located in the distal of apical third of the corresponding } \\
\text { third molar. Crown morphology distinct. }\end{array}$ \\
\hline $50 / \mathrm{F}$ & Pano & $\begin{array}{l}\text { Maxillary left } \\
\text { quadrant }\end{array}$ & Toothlike structure & Unerupted & $\begin{array}{l}\text { Two toothlike structures distal to the fully erupted } \\
\text { maxillary left third molar. No CT available for close } \\
\text { evaluation. The outline of the tooth was not clearly } \\
\text { demonstrated on the panoramic radiograph. The } \\
\text { appearance was suggestive of fourth and fifth molars. }\end{array}$ \\
\hline 19/M & Pano & $\begin{array}{l}\text { Maxillary right } \\
\text { quadrant }\end{array}$ & Toothlike structure & Unerupted & $\begin{array}{l}\text { Fully formed tooth distal to the maxillary right thir } \\
\text { molar. Located in the maxillary tuberosity. }\end{array}$ \\
\hline $45 / \mathrm{F}$ & Pano & $\begin{array}{l}\text { Maxillary right } \\
\text { quadrant }\end{array}$ & $\begin{array}{l}\text { Small and not } \\
\text { toothlike }\end{array}$ & Unerupted & $\begin{array}{l}\text { Radiopaque entity with the appearance of enamel at the } \\
\text { tip. Distal to the maxillary left third molar. }\end{array}$ \\
\hline
\end{tabular}

Pano: panoramic radiography, CBCT: cone-beam computed tomography, CT: computed tomography 

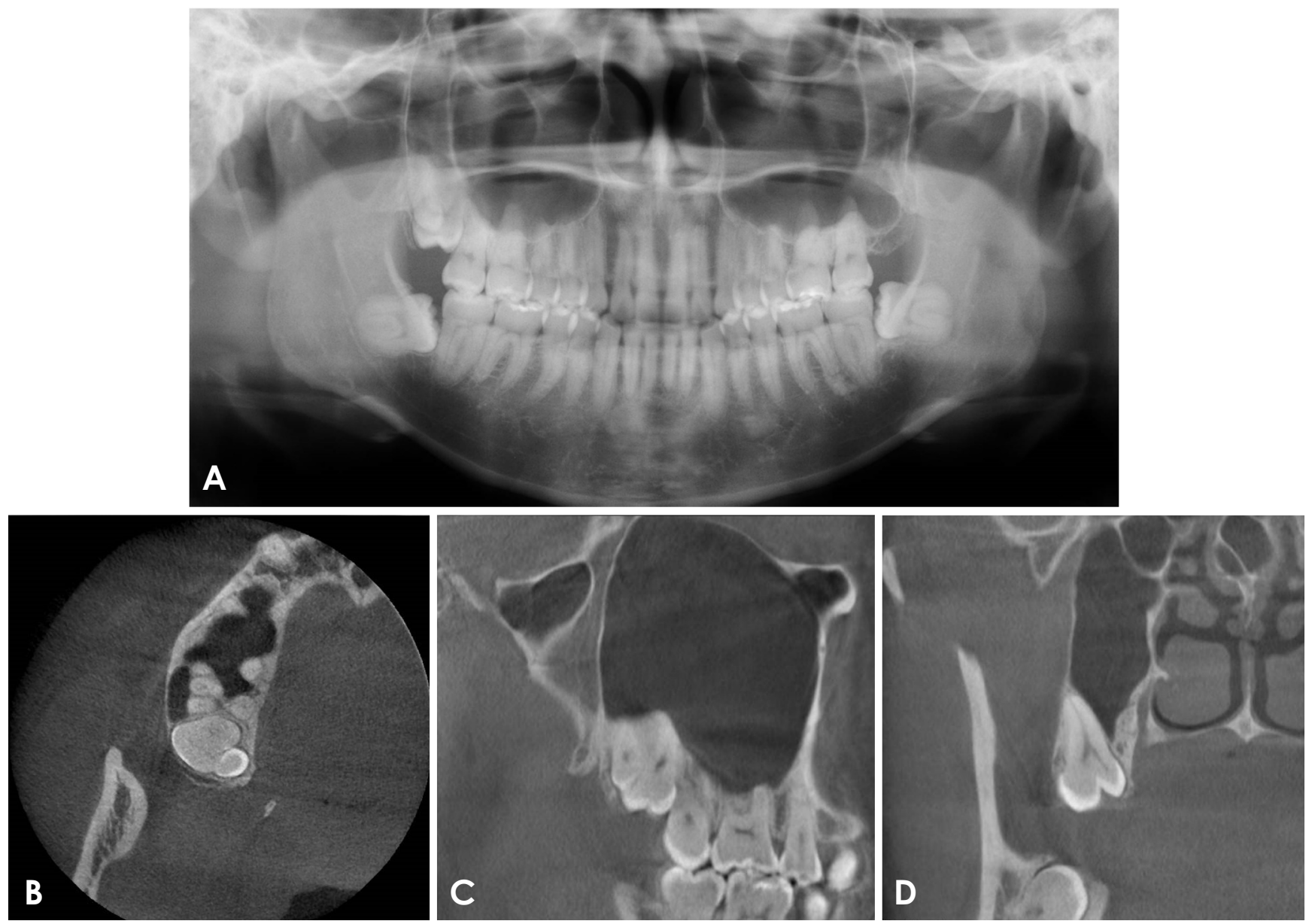

Fig. 3. A. Panoramic radiograph shows a fourth molar overlapping the maxillary right third molar. Cone-beam computed tomographic images demonstrate a fourth molar distopalatal to the maxillary right third molar (B) and a fused tooth connecting with the third molar by the dental pulp (C and D).

\section{Discussion}

Fourth molars are also referred to as distomolars, which suggests that they are anatomically located distal to the third molars. In contrast, paramolars are supernumerary teeth located on the side of the molars. ${ }^{10}$ Fourth molars are the second most common type of supernumerary tooth. ${ }^{11-13}$ They are usually solitary and impacted distal to the third molar, ${ }^{11,12,14}$ and are more often located in the maxilla than in the mandible..$^{9,11,15}$ Our study similarly found that fourth molars had a predilection for the maxilla. The prevalence of fourth molar has been reported to be between $0.1 \%$ and $3.8 \% .^{5-7}$ In our study, the prevalence was found to be $0.32 \%$. The prevalence of fourth molars in our study is higher than that reported by Kaya et al., who found a prevalence of $0.26 \% .^{6}$ In our study, the male-to-female ratio was 1:0.98, and $82 \%$ of the fourth molars were unerupted. The male-tofemale ratio in our study agrees with that reported by Kaya et al. ${ }^{6}$ and Shahzad et al. ${ }^{9}$

Differences in sex predilection may be related to the ethnicity of the study population. ${ }^{6}$ Harris and Clark reported that fourth molars were the most common supernumerary teeth in black patients and that black American patients were 9 times more likely to have supernumerary teeth than white patients. ${ }^{9,16}$

A large percentage of fourth molars are unerupted, and these teeth are mostly diagnosed based on radiographic findings. It is possible to encounter difficulties while attempting to decide on a borderline case (Fig. 1), where it cannot be clearly determined whether a tooth is a fourth molar, a third molar, or an odontoma. We encountered such scenarios during our study, for which the authors were not able to establish a consensus. Such cases were not classified as fourth molars, and were excluded from our study. It is necessary for clinicians to be aware of such confounding cases. Periapical radiographs, panoramic radiographs, and 


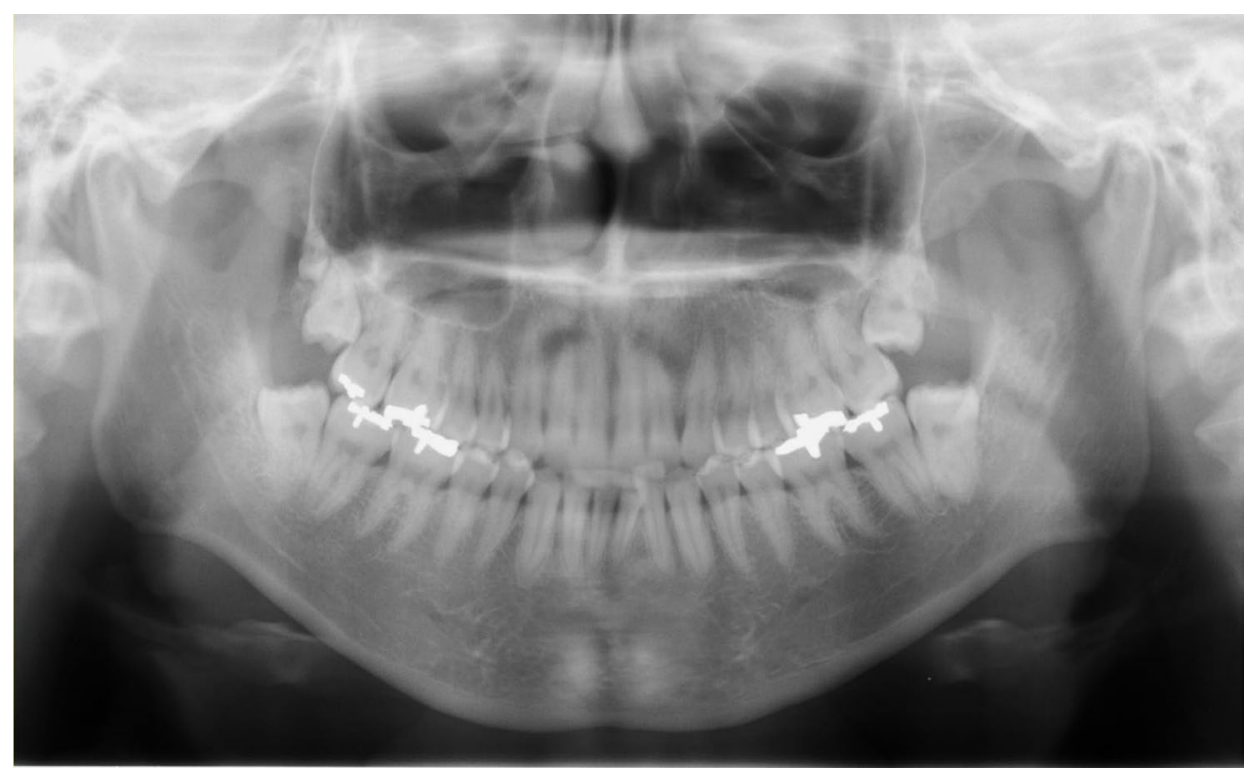

Fig. 4. Fully-formed fourth molar associated with the distal surface of the maxillary right third molar in a patient with cleidocranial dysostosis.

CBCT are useful for determining the morphology of an unerupted supernumerary tooth because, in addition to being unerupted, fourth molars may also present an abnormal morphology. Fourth molars are often found during routine radiographic examinations. ${ }^{6}$ When supernumerary teeth erupt and are clinically evident, they can cause pathologies such as delayed eruption, tooth displacement, crowding, periodontal disease, increased incidence of dental caries in adjacent teeth, root resorption of adjacent teeth, and cyst formation. ${ }^{2,17,18}$ In the present study, some cases of mucous retention cyst were associated with a fourth molar. Furthermore, many of the cases of fourth molars in our study were small and intricately related to the maxillary tuberosity and the floor of the maxillary sinus. This anatomic location is difficult to access and poses a surgical challenge for extraction of a fourth molar.

It has been suggested that in cases in which surgical risks outweigh the benefits of extraction, fourth molars should be monitored regularly by clinical and radiographic observation, ${ }^{8}$ especially if no pathological conditions or complications are present. In the present studies, no cases presented with enlargement of a dental follicle, which may have suggested a dentigerous cyst; this determination can be supported through follow-up using X-ray images. Two cases in our study presented fusion of the roots of the fourth molar with the adjacent third molar (Fig. 3). Care is therefore needed when extracting third molars associated with fourth molars.

Supernumerary teeth can be seen in various syndromes and developmental disorders, such as cleidocranial dysostosis, Gardner syndrome, and Ehlers-Danlos syndrome. ${ }^{3,4}$ One of the 87 patients with a fourth molar in our study had cleidocranial dysostosis (Fig. 4). Non-syndromic fourth molars are more common than syndromic fourth molars. ${ }^{2,4}$

In the present study, we retrospectively reviewed a total of 26,721 cases with imaging obtained at the Department of Oral Diagnosis and Dentomaxillofacial Radiology of Okayama University Hospital between January 2013 and December 2017. The prevalence of fourth molars in the study population was $0.32 \%$, and fourth molars occurred with approximately equal frequency in males and females. Fourth molars were more common in the maxilla and were predominantly unerupted and small.

\section{References}

1. Pippi R. Odontomas and supernumerary teeth: is there a common origin? Int J Med Sci 2014; 11: 1282-97.

2. Rajab LD, Hamdan MA. Supernumerary teeth: review of the literature and a survery of 152 cases. Int J Paediatr Dent 2002; 12: 244-54.

3. Patchett CL, Crawford PJ, Cameron AC, Stephens CD. The management of supernumerary teeth in childhood-a retrospective study of practice in Bristol Dental Hospital, England and Western Dental Hospital, Sydney, Australia. Int J Paediatr Dent 2001; 11: 259-65.

4. Fernández Montenegro P, Valmaseda Castellón E, Berini Aytés L, Gay Escoda C. Retrospective study of 145 supernumerary teeth. Med Oral Patol Oral Cir Bucal 2006; 11: E339-44.

5. Harel-Raviv M, Eckler M, Raviv E, Gornitsky M. Fourth mo- 
lars: a clinical study. Dent Update 1996; 23: 379-82.

6. Kaya E, Güngör K, Demirel O, Özütürk Ö. Prevalence and characteristics of non-syndromic distomolars: a retrospective study. J Investig Clin Dent 2015; 6: 282-6.

7. Dang HQ, Constantine S, Anderson PJ. The prevalence of dental anomalies in an Australian population. Aust Dent J 2017; 62: $161-4$.

8. Scarfe WC, Farman AG, Sukovic P. Clinical applications of cone-beam computed tomography in dental practice. J Can Dent Assoc 2006; 72: 75-80.

9. Shahzad KM, Roth LE. Prevalence and management of fourth molars: a retrospective study and literature review. J Oral Maxillofac Surg 2012; 70: 272-5.

10. Rahnama M, Szyszkowska A, Pulawska M, Szczerba-Gwordz J. A rare case of retained fourth molar teeth in maxilla and mandible. Case report. Curr Issues Pharm Med Sci 2014; 27: 118-20.

11. Grimanis GA, Kyriakides AT, Spyropoulos ND. A survey on supernumerary molars. Quintessence Int 1991; 2: 989-95.

12. Ruprecht A, Batniji S, el-Neweihi E. Incidence of supernumerary teeth. Ann Dent 1984; 43: 18-21.

13. McMenamin JP, Hart D. Paramolars: a case report. N Y J Dent 1985; 33: 209.

14. Fisher SE. Maxillary sixth molars. Br Dent J 1982; 152: 356.

15. Piattelli A, Tetè S. Bilateral maxillary and mandibular fourth molars. Report of a case. Acta Stomatol Belg 1992; 89: 57-60.

16. Harris EF, Clark LL. An epidemiological study of hyperdontia in American blacks and whites. Angle Orthod 2008; 78: 460-5.

17. Batra P, Duggal R, Parkash H. Non-syndromic multiple supernumerary teeth transmitted as an autosomal dominant trait. J Oral Pathol Med 2005; 34: 621-5.

18. Dubuk AN, Selvig KA, Tellefsen G, Wikesjö UM. Atypically located paramolar. Report of a rare case. Eur J Oral Sci 1996; 104: $138-40$. 